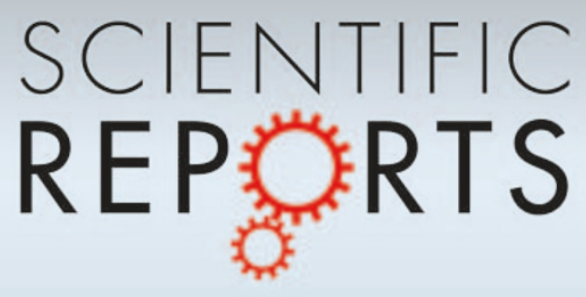

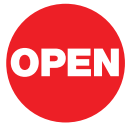

SUBJECT AREAS: ENERGY

ENVIRONMENTAL CHEMISTRY

GREEN CHEMISTRY

MATERIALS CHEMISTRY

Received

27 March 2012

Accepted

22 May 2012

Published

12 June 2012

Correspondence and requests for materials should be addressed to I.H. (i.honma@tagen. tohoku.ac.jp)

\section{Rechargeable quasi-solid state lithium battery with organic crystalline cathode}

\author{
Yuki Hanyu \& Itaru Honma
}

Utilization of metal-free low-cost high-capacity organic cathodes for lithium batteries has been a long-standing goal, but critical cyclability problems owing to dissolution of active materials into the electrolyte have been an inevitable obstacle. For practical utilisation of numerous cathode-active compounds proposed over the past decades, a novel battery construction strategy is required. We have designed a solid state cell that accommodates organic cathodic reactions in solid phase. The cell was successful at achieving high capacity exceeding $200 \mathrm{mAh} / \mathrm{g}$ with excellent cycleability. Further investigations confirmed that our strategy is effective for numerous other redox-active organic compounds. This implies hundreds of compounds dismissed before due to low cycleability would worth a re-visit under solid state design. ithium ion batteries (LIB) have traditionally been used for portable electronic devices due to low weight, high energy density but high price. However, recent emerging demands for secondary batteries extend to largescale applications such as electric vehicles and peak load leveling installations due to environmental concerns and energy security ${ }^{1}$. However, large-scale installations using current methods would leave large ecological footprint and face resource restrictions, since current cathodes use rare metals such as cobalt. Redox-active organic materials do not require such material and also possess large energy density, primarily owing to their two-electron reactions. Many of such compounds are low-cost, and some are even biomass in origin ${ }^{2}$. Furthermore, if organic cathode can be integrated in a solid-state lithium batteries that accommodate energydense metallic lithium anode and do not require flammable organic electrolytes, it would offer possible solution for a much needed energy-dense, durable, low-cost and safe large-scale lithium battery . $^{3,4}$

While properties of organic cathodes are desirable, irreversible reaction by singly reduced radical anions, low conductivity, and dissolution issues currently pose critical safety and cyclability problems ${ }^{5,6}$. Some of the reported strategies for improvement include optimization of molecular designs, tuning of solubility in electrolyte, use of carbon additives and anchoring or polymerization of active compound. Stabilization of radical anions by expansion of conjugation or introduction of peripheral substituents are effective and common ${ }^{6-10}$, but this alone does not solve the dissolution issue. Tuning of solubility, for example, by $\pi$ - $\pi$ stacking or choosing low-solubility electrolyte $^{11}$, high proportions ( $\left.~ 80 \mathrm{wt} . \%\right)$ of conductive or polyethylene oxide (PEO) additives sacrifice the overall energy density and yet only delay cathode dissolution ${ }^{7,12,13}$. In this regard, an all-solid battery design that offers a fundamental solution to dissolution issue is lucrative, but precedents remain very limited to few specific compounds 9 . Recent studies aims to achieve "all-solid" by anchoring active ingredients on nanomaterials ${ }^{14}$ or the use of polymeric organic cathodes ${ }^{15-17}$, but these methods tend to block $\mathrm{Li}^{+}$conduction paths ${ }^{18}$. Moreover, if potentials of organic cathodes - low cost, large capacity and molecular design versatility - are to be fully exploited, a generally applicable methodology that accommodates any monomeric, polymeric or composite cathode must be devised.

Here, we report a high energy density all-solid monomeric organic cathode lithium cell that possesses high cycleability. A novel cell design is introduced, which prevents dissolution of organic cathode compounds. The cell features totally encapsulated cathode, PEO layer, quasi-solid electrolyte and controlled electrolyte-anode interface (Figure 1A). Tetracyanoquinodimethane (TCNQ) cathode is primarily investigated for its relatively high redox potentials and abundance of literature $\mathrm{e}^{19-21}$.

\section{Results}

A lithium cell using 1-ethyl-3-methyl-imidazolium bis(trifluoromethylsulfonyl)imide ([EMIm][Tf 2 N]) roomtemperature ionic liquid (RTIL) composite quasi-solid electrolyte and TCNQ cathode in our novel cell construction reached the theoretical capacity of $262 \mathrm{mAh} / \mathrm{g}_{\text {-TCNQ }}$ (Figure $1 \mathrm{~B}$ ) at 323K, $0.2 \mathrm{C}$ discharge rate between 

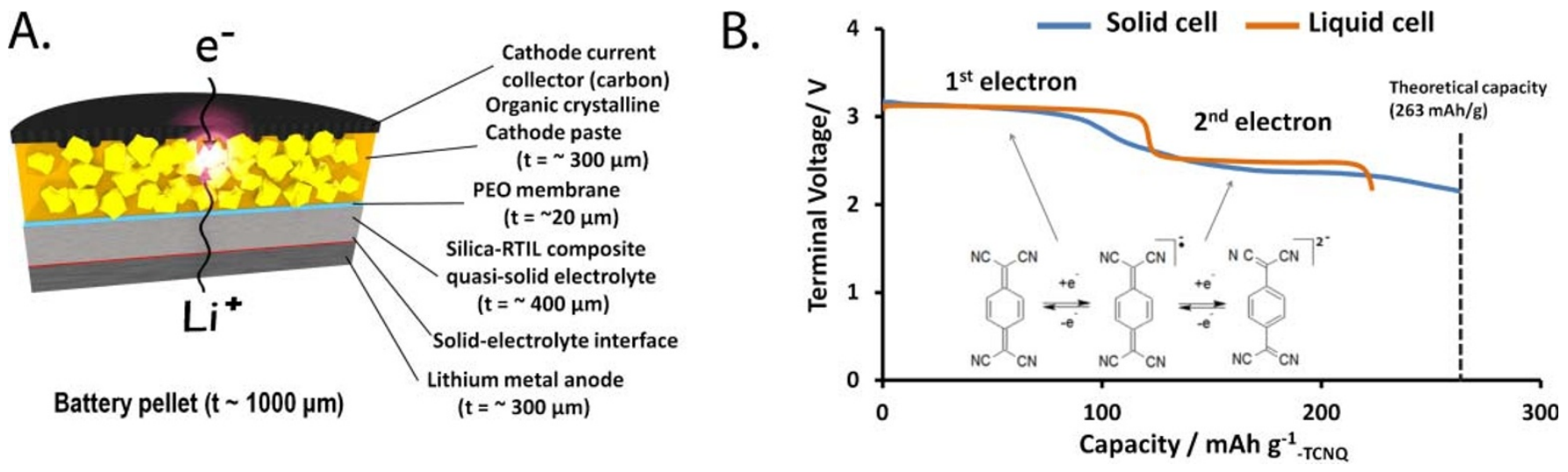

Figure 1 The principles of bulk organic all-solid lithium cell. (A) The cross-section of an organic crystalline all-solid battery - the cathode contains large surface-area carbon current collector, RTIL and organic crystals in a sealed environment. The carbon current collector provides abundant tri-phase boundaries, RTIL secures lithium ion conduction paths to the organic crystals (active cathode material). The PEO membrane and silica-RTIL composite solid electrolyte separates the cathode from metallic lithium anode. (B) A comparison of discharge curves between solid cell and liquid cell portrays that liquid cell does not reach its theoretical capacity due to dissolution. The characteristic two-step profile correspoinding to the first and second redox reaction of TCNQ is evident for both.

$2.1 \mathrm{~V}-4.0 \mathrm{~V}$. At room temperature, the initial capacity was $215.8 \mathrm{mAh} / \mathrm{g}_{\text {-TCNQ }}$ and after 100 cycles, $\sim 170 \mathrm{mAh} / \mathrm{g}_{\text {-TCNQ }}$ of capacity was retained (Figure 2A). Another cell using 1-butyl-2-methyl pyrrolidinium bis(trifluoromethylsulfonyl)imide ([BMP] $\left.\left[\mathrm{Tf}_{2} \mathrm{~N}\right]\right)$ RTIL composite quasi-solid electrolyte recorded $73 \%$ capacity retention over 170 cycles at $0.2 \mathrm{C}$ rate, $323 \mathrm{~K}$ (Figure $2 \mathrm{~B}$ ). Comparable cycleability was observed at $2 \mathrm{C}$ rate too (Supplementary Fig. S5). In general, when the temperature was elevated, test cells recorded higher initial capacities but faster capacity loss. When the active material content was high, the capacity fading was more rapid despite comparable initial specific capacities. A total cell energy density of
$120 \mathrm{Wh} / \mathrm{kg}_{\text {-cell }}$ was achieved for a cell that tolerated more than 100 cycles. $200 \mathrm{Wh} / \mathrm{kg}_{\text {-cell }}$ was also achieved when cycleability was sacrificed.

\section{Discussion}

The most prominent feature of an all-solid cell is the use of solid electrolyte. However, low temperature tolerance of organic cathodes (The TG-DTA measurement of the TCNQ cathode paste confirmed thermal stability only up to $\sim 200$ degrees, Supplementary fig. S1) precludes many of the known ceramic solid electrolytes such as thioLISICON, LIPON, $\mathrm{Li}_{3} \mathrm{~N}$ and $\mathrm{LLT}^{22-24}$. A suitable solid electrolyte in

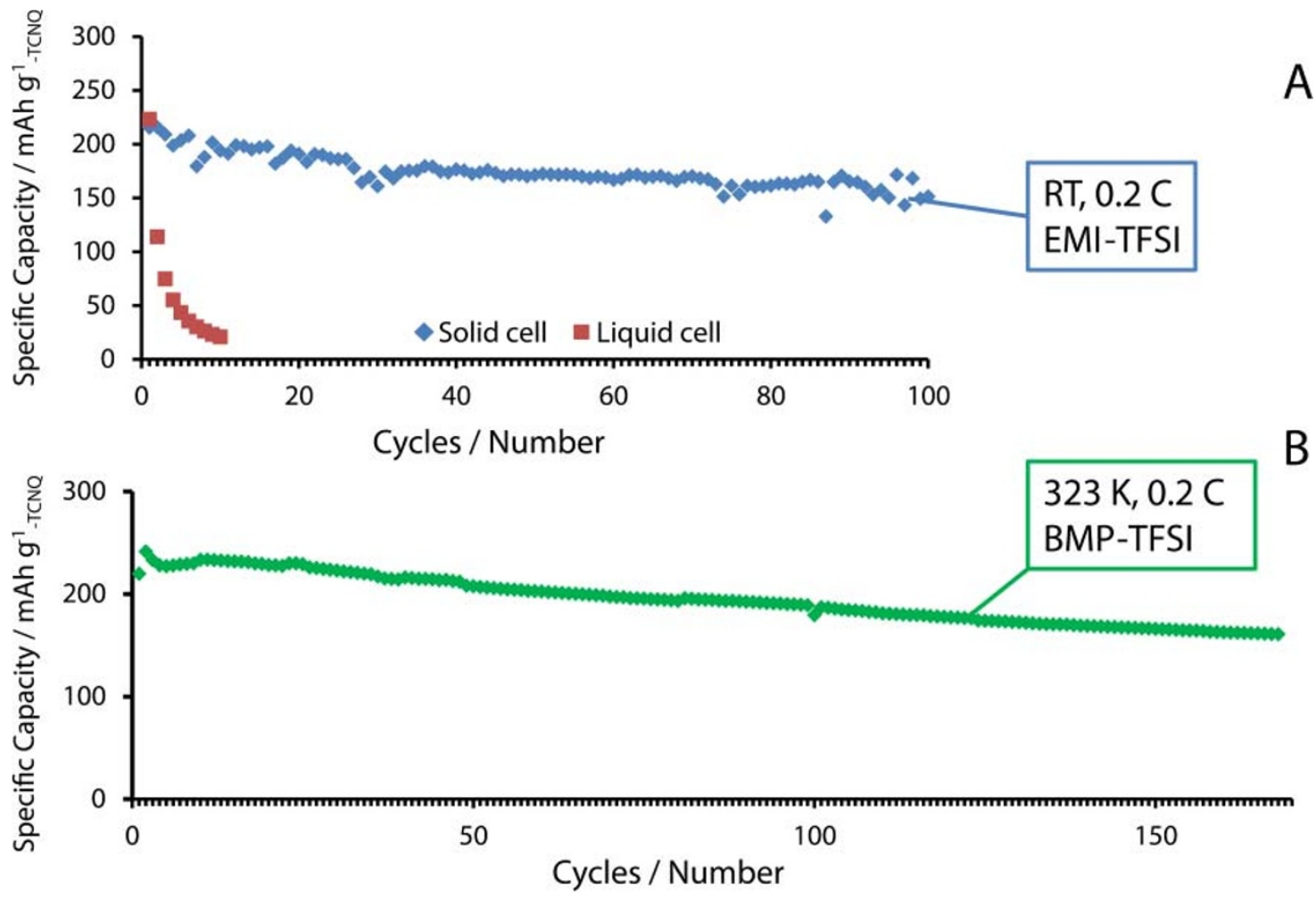

Figure $2 \mid$ The performance of all-solid TCNQ cell - cycleability. (A) The graph compares the cycleability of EC/DEC organic electrolyte liquid cell and [EMIm] $\left[\mathrm{Tf}_{2} \mathrm{~N}\right]$ composite solid cell cycled at $0.2 \mathrm{C}$ rate at room temperature. The rapid cathode degradation in liquid cell starkly contrasts to the stability of an all-solid cell. (B) A solid cell using $[\mathrm{BMP}]\left[\mathrm{Tf}_{2} \mathrm{~N}\right]$ composite electrolyte tolerated extended charge-discharge cycles. At the $60^{\text {th }}$ cycle, the capacity was still over $200 \mathrm{mAh} / \mathrm{g}_{-\mathrm{TCNQ}}$. 
this case must display sufficiently high ionic conductivity below $340 \mathrm{~K}$, suppress dendritic formation on the lithium anode side, and prevent cathode dissolution. While the use of ceramic conductors remains the ultimate goal for large-scale batteries, known ceramic ionic conductors fall slightly short of this purpose. The one with highest known $\mathrm{Li}^{+}$conductivity, $\mathrm{Li}_{10} \mathrm{GeP}_{2} \mathrm{~S}_{12}{ }^{23}$, is unstable toward Li metal and in general, sulfide glass electrolytes has serious safety concerns (reaction with water releases $\mathrm{H}_{2} \mathrm{~S}$ ). On the contrary, a "saggy sand" quasi-solid electrolyte containing fumed silica nanoparticles and RTIL possess some attractive properties in terms of cost, safety and resource restrictions ${ }^{25,26}$. Nonetheless, this saggy sand electrolyte still allows some cathode dissolution to occur. In addition, its electrochemical window of many RTIL's such as [EMIm] $\left[\mathrm{Tf}_{2} \mathrm{~N}\right.$ ] does not cover $\mathrm{Li} / \mathrm{Li}^{+}$redox potential. This causes a resistive solidelectrolyte interface (SEI) layer of decomposed products to form on the metallic lithium anode surface and leads to drop in cell voltage and cycleability. To mitigate these issues, a 3-layer composite electrolyte was designed and implemented.

A three-layer solid electrolyte features $\sim 20 \mu \mathrm{m}$ thick PEO layer on the cathode side, middle $\sim 400 \mu \mathrm{m}$ thick RTIL-Silica "saggy sand" layer, and a controlled SEI on the anode side. PEO film is soluble in most RTIL's and upon cell assembly, the PEO layer transforms into a highly viscous thin matrix of PEO-RTIL-silica mixture that glues solid electrolyte with cathode and prevents dissolution. The bulk of the solid electrolyte forming the middle layer provides structural integrity to the cell. The [EMIm] $\left[\mathrm{Tf}_{2} \mathrm{~N}\right]$-Silica composite electrolyte has sufficiently high ionic conductivity around $1 \times 10^{-3} \mathrm{\sigma} / \mathrm{cm}$ at $298 \mathrm{~K}^{25}$. The third SEI layer on anode side was prepared by applying small amount $(5 \mu \mathrm{l})$ of EC/DEC on the anode surface before cell assembly to pre-occupy the surface with desirable $\mathrm{Li}^{+}$conductive decomposition products. There was also a possibility that added EC/DEC increases the $\mathrm{Li}^{+}$conductivity by acting as less-viscous co-solvent with $[\mathrm{EMIm}]\left[\mathrm{Tf}_{2} \mathrm{~N}\right]$. This technique traces the work by Takagi et al, which introduced $\sim 10$ vol. $\%$ of organic solvents to RTIL to form an SEI to improve charge-discharge properties of anode ${ }^{27}$. Hence, a successfully constructed 3-layer quasi-solid electrolyte pellet would block cathode leaching, possess high ionic conductivity, and form a stable low resistance SEI on the anode.

The quasi-solid electrolyte, PEO membrane, TCNQ cathode paste and current collector were stacked in this order and compressed in a die at $100 \mathrm{MPa}$ pressure to form a combined pellet that encapsulated the cathode paste (Figure $3 \mathrm{~A}$ ). The combined pellet and metallic lithium were integrated in a coin-type cell in Ar atmosphere to construct a cell for characterisation and measurement (Supplementary fig. S2). A charge-discharge experiment was conducted between $2.1 \mathrm{~V}$ and $4.0 \mathrm{~V}$ at $323 \mathrm{~K}$ at $0.2 \mathrm{C}$ charge rate. The full theoretical capacity of $263 \mathrm{mAh} / \mathrm{g}_{\text {-TCNQ }}$ was obtained from this cell (Figure 1B). The SEM micrograph of TCNQ paste identified bulk crystals that were $20 \sim 50 \mu \mathrm{m}$ in size, surrounded by coagulations of $\mathrm{KB}$ (Figure 3B). This was further confirmed by nitrogen signals in EDX mapping. Local charge accumulation did not occur even without gold deposition, implying that carbon conductive additive
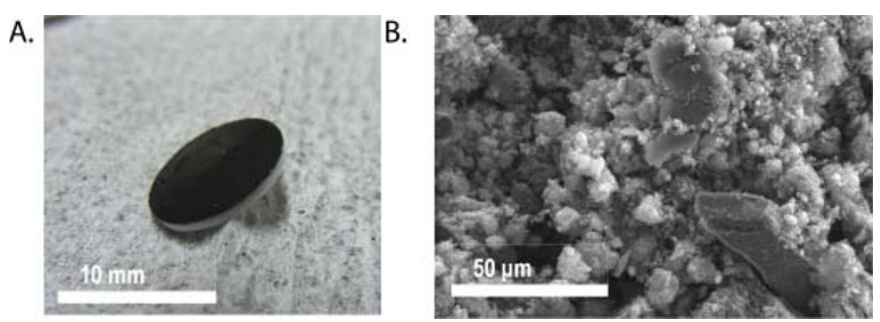

Figure 3 The physical features of bulk organic all-solid lithium cell. (A) A photograph of the actual pellet illustrated in Figure 1A; the diameter is $10 \mathrm{~mm}$ and thickness is $\sim 700 \mu \mathrm{m}$ before Li anode contact. (B) The SEM micrograph of the TCNQ cathode paste. A large $(\sim 50 \mu \mathrm{m})$ TCNQ crystal is visible. provided sufficient electronic conductivity. When the cell is assembled, the tri-phase boundary of TCNQ, KB and RTIL forms to join the electronic and $\mathrm{Li}^{+}$conduction paths and the active cathode material. In contrast to $\mathrm{LiCoO}_{2}$ or $\mathrm{LiNiO}_{2}$ cathode materials, there have been very few studies on the mechanism of organic cathode reactions ${ }^{9}$, and how organic crystals react with lithium ions is largely unknown. A study conducted by Senoh et al on an organic cathode in saturated catholyte concluded that crystalline organic compounds can act as cathode material by a dissolution-mediated process $^{8}$. This may be the case for a liquid cell - the clear-cut flat plateaus in the discharge profile of a liquid cell near $2.5 \mathrm{~V}$ and $3.1 \mathrm{~V}$ are suggestive of molecular reactions from TCNQ into LiTCNQ and then LiTCNQ into $\mathrm{Li}_{2}$ TCNQ. On the contrary, "plateaus" from allsolid cells resemble that of an entropy-determined reaction profile of solid $\mathrm{LiCoO}_{2}$. In addition, dissolution mediated process is likely to result in growth of TCNQ crystals in a mechanism akin to Ostwald ripening, which would quickly degrade electrical contacts in cathode. Thus, it is hypothesized that an all-solid cells configuration lets cathodic reactions to occur in solid-state, which results in significant enhancement in cycleability.

The cycleability was investigated at $0.2 \mathrm{C}$ rate at room temperature and compared against liquid cell. A test cell containing 50 wt.\% TCNQ cathode paste retained nearly $170 \mathrm{mAh} / \mathrm{g}$ of capacity after 100 cycles and the discharge profile still exhibited TCNQ's doublestep curve characteristic of a two-electron reaction (Figure 4A). On the contrary, the liquid cell control group lost $\sim 87 \%$ of its capacity by the 5 th cycle (Figure 2A, Supplementary fig. S3). The clear colourless EC/DEC electrolyte turning turbid deep green and proportional shrinking of discharge profiles over cycles suggested cathode degradation by dissolution. This result alone demonstrates the notable effectiveness of adopting all-solid design for organic cathode batteries.

THBQ and DDQ based cathodes were also tested in our all-solid cells. THBQ possesses larger theoretical capacity $(311.5 \mathrm{mAh} /$ $\left.\mathrm{g}_{\text {-THBQ}}\right)^{2}$ and DDQ exhibits high redox potential and moderate theoretical capacity $\left(236 \mathrm{mAh} / \mathrm{g}_{-\mathrm{DDQ}}\right.$ at $3.5 \mathrm{~V}$ and $3.3 \mathrm{~V}$ vs. Li/ $\mathrm{Li}^{+}$). DDQ-as-cathode was investigated before, but ultimately dismissed due to critically low cycleability ${ }^{20}$. Initial investigations on THBQ succeeded in maintaining discharge capacities of $280 \mathrm{mAh} /$ $\mathrm{g}_{\text {-THBQ }}$ for several cycles and a similar experiment on DDQ recorded the initial capacity of $170 \mathrm{mAh} / \mathrm{g}_{-\mathrm{DDQ}}$ with a cathode, which DDQ content was $94.4 \%$. Details will follow in a future publication.

To further characterise the all-solid cells and establish a strategy for improvements, the effect of active material content, temperature dependence, charge-discharge rate and tuning of solid electrolyte to battery performance were investigated. First, test cells that contained 47.6 wt.\% TCNQ cathodes cycled at room temperature and $323 \mathrm{~K}$ were compared. The discharge capacities of the earliest cycles was greater at $323 \mathrm{~K}$ than that at room temperature, but by the $20^{\text {th }}$ cycle, the capacities were $\sim 200 \mathrm{mAh} / \mathrm{g}_{\text {-TCNQ }}$ at room temperature and $\sim 130 \mathrm{mAh} / \mathrm{g}_{\text {-TCNQ }}$ at $323 \mathrm{~K}$ (Figure $5 \mathrm{~A}$ ). The general shape of charge-discharge profiles was unchanged, implying that irreversible side reactions or cathode degradation did not occur. Rather, proportional shrinking of charge-discharge profiles implying gradual loss of the cathode compound was observed. Therefore we conclude, although high temperature is beneficial for obtaining high initial capacity, it causes accelerated cathode degradation, probably because the cathode containment is incomplete and our 3-layer quasi-solid electrolyte still has a room for improvement.

The effect of cathode composition was investigated by constructing 3 test cells with cathodes containing 88.7 wt.\%, $47.6 \mathrm{wt} . \%$ and 29.1 wt.\% TCNQ and evaluating the battery performance at $0.2 \mathrm{C}$, $323 \mathrm{~K}$. All cells exhibited comparable initial discharge capacities exceeding $200 \mathrm{mAh} / \mathrm{g}_{\text {-TCNQ}}$, but different cycleabilities. The cell with higher TCNQ content degraded faster as shown in Figure 5B. Their discharge profiles revealed that rapid capacity loss of $88.7 \mathrm{wt} . \%$ 

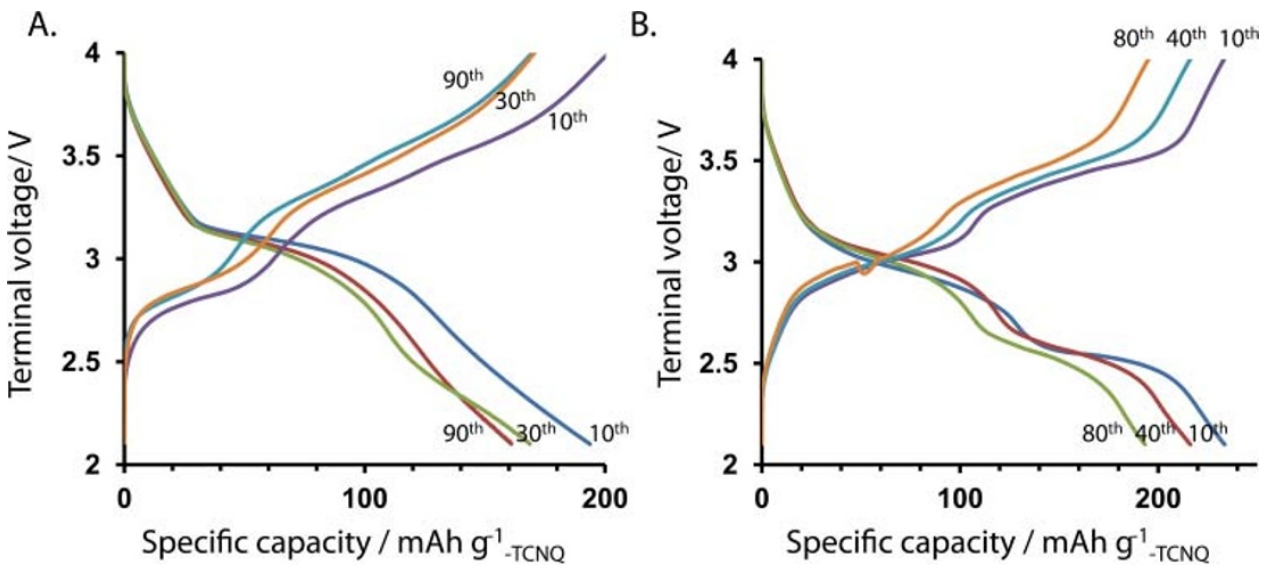

Figure $4 \mid$ The performance of all-solid TCNQ cell - charge-discharge profiles. (A) The charge-discharge profile of the $10^{\text {th }}, 30^{\text {th }}$ and $90^{\text {th }} \mathrm{cycles}$ at room temperature (fluctuated between $290 \mathrm{~K} \sim 300 \mathrm{~K}$ ) for the cell described in Figure 2A suggests a stable reversible reaction. The $90^{\text {th }}$ discharge profile roughly traces the $30^{\text {th }}$ profile. (B) The $10^{\text {th }}, 40^{\text {th }}$ and $80^{\text {th }}$ charge-discharge profiles for the cell described in Figure $2 \mathrm{~B}$ show proportional shrinking that suggest minimal side reactions and certain amount of cathode material loss. The difference between (A) and (B) is thought to arise from temperature and contact between KB and LiTCNQ crystals.

TCNQ cell primarily stemmed from the rapid increase in polarization between charging and discharging for the second plateau, which corresponded to the reaction of LiTCNQ to $\mathrm{Li}_{2}$ TCNQ (Supplementary fig. S4). This contrasted to aforementioned proportional shrinkage owing to dissolution. It is noteworthy that even for $47.6 \mathrm{wt} \%$ TCNQ cathode cells, the second discharge plateau is not as flat as the one in a liquid cell. The nature of second plateau becomes more conspicuous in the form of $\mathrm{dQ} / \mathrm{dV}$ plot, which shows peculiar peaks for the second discharge reaction (Supplementary fig. S5). In this plot, the discharging peak for the $2^{\text {nd }}$ redox reaction is stochastic, but the charging peak is clean. We related this phenomenon to high resistivity of $\mathrm{Li}_{2}$ TCNQ or LiTCNQ/ $\mathrm{Li}_{2}$ TCNQ mixture and difficulty for $\mathrm{Li}^{+}$to access reaction centres in solid-phase reactions. In a liquid cell configuration, it is expected that $\mathrm{Li}^{+}$has more facile access to reaction centres and the $2^{\text {nd }}$ step of its discharge profile becomes flatter.

The cell performances at higher rate $(2 \mathrm{C})$ were compared at $323 \mathrm{~K}$ and room temperature (Supplementary fig. S6). The initial capacities of cells at both temperatures exceeded $200 \mathrm{mAh} / \mathrm{g}$. Compared to measurements at $0.2 \mathrm{C}$, the initial capacities were slightly smaller, but cycleabilities were comparable. The potential profiles nearly identical to that at lower charge rates indicated that anticipated cathodic reaction was proceeding. The overall temperature dependence of cells cycled at $2 \mathrm{C}$ was the same as that at $0.2 \mathrm{C}-\mathrm{a}$ cell at lower temperature has smaller initial specific capacity, but it decays less in the long run.

In the next set of experiments, the RTIL's used for the quasi-solid electrolyte was varied and their capacities and cycleabilities were compared. In this study, [EMIm] $\left[\mathrm{Tf}_{2} \mathrm{~N}\right],[\mathrm{DEME}]\left[\mathrm{Tf}_{2} \mathrm{~N}\right],[\mathrm{PP} 13]$ $\left[\mathrm{Tf}_{2} \mathrm{~N}\right]$ and $[\mathrm{BMP}]\left[\mathrm{Tf}_{2} \mathrm{~N}\right]$ were compared by preparing 4 test cells based on each. The proper names and molecular structures are given in Supplementary figure S7. All test cells exhibited similar initial capacities exceeding $200 \mathrm{mAh} / \mathrm{g}_{-\mathrm{TCNQ}}$, but various rates of capacity fading were recorded in the increasing order of $[\mathrm{BMP}]\left[\mathrm{Tf}_{2} \mathrm{~N}\right]<$ $[\mathrm{PP} 13]\left[\mathrm{Tf}_{2} \mathrm{~N}\right]<[\mathrm{DEME}]\left[\mathrm{Tf}_{2} \mathrm{~N}\right]<[\mathrm{EMIm}]\left[\mathrm{Tf}_{2} \mathrm{~N}\right]$. This appears to be the reverse order of the viscosities of these RTIL's, though the exact determinant for cell cycleability needs further investigation. We expect solubility product also play a major role concerning the cycleability. Among these RTIL's, the best cycleability was obtained from the cell using $[\mathrm{BMP}]\left[\mathrm{Tf}_{2} \mathrm{~N}\right]$. Throughout the cycling experiment, the shape of charge-discharge profiles was constant except proportional shrinking - this rules out cathode degradation by side reactions but indicates gradual loss of active material (Figure 4B). Although polarization between charging and discharging was relatively large at $\sim 0.4 \mathrm{~V}$, the cell's capacity retention was $73 \%$ after 170
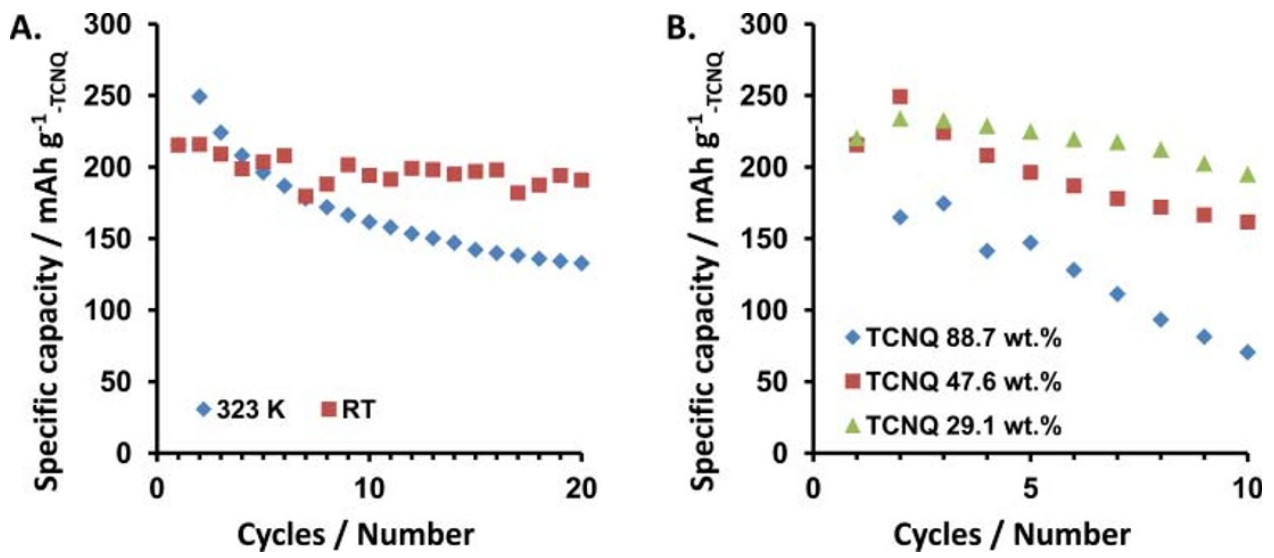

Figure 5 The composition and temperature dependence on cell cycleability. (A) An experiment comparing $323 \mathrm{~K}$ and RT showed that cells at elevated temperature exhibits higher initial capacities but lower cycleability. (B) A comparison of 3 cells using [EMIm] [Tf2N] composite, cycled at $323 \mathrm{~K}$ and $0.2 \mathrm{C}$ rate reveals that higher TCNQ fraction results in lower cycleability despite comparable initial capacity. 
cycles, which is an unprecedented cyclic capability for TCNQ cathode cell (Figure 2B).

When a cell was disassembled after extended charge-discharge experiment, the PEO layer, which has transformed into a viscous material, mostly remained in its place and no observable diffusion through the electrolyte or cathode was found. The initially opaquewhite solid electrolyte slightly acquired the yellow colour of TCNQ, which also supports our speculation that further improvements in cycleability is possible by more rigorous control of cathode dissolution. In addition, further significant improvements in cell performance are anticipated by thinning the solid electrolyte from the current $\mathrm{t} \sim 400 \mu \mathrm{m}$. This must be investigated bearing in mind the physical and mechanical properties of the solid electrolyte.

In conclusion, we have demonstrated the effectiveness of an allsolid approach for using organic cathodes, many of which have been previously dismissed for being excessively soluble. Given these results, we consider re-visiting such compounds a worthwhile effort. TCNQ-based all-solid cells have reached the theoretical capacity and hence reversible cathodic reactions were demonstrated. Besides molecular designing of cathode compounds, we believe further room for improvements exist in the electrolyte and cathode preparation. The basic specifications of test cells, "all-solid, $\sim 300 \mu \mathrm{m}$ thick cathode, $50 \sim 80$ wt.\% active material" offers a strong case for adopting organic cathodes for large-scale rechargeable lithium batteries for mass energy storage applications. Further improvements would be found in integration of polymeric or sulphur cathode, or the use of improved ceramic solid electrolytes.

\section{Methods}

Synthesis and Preparation: TCNQ and DDQ were used as received without further purification. THBQ as received was dried at $343 \mathrm{~K}$ under vacuum overnight prior to use. Typically, $\sim 15 \%$ weight loss was recorded upon drying. Kynar-2801 polyvinylidene fluoride ("PTFE", MW $=\sim 120,000$, Mitsui Du Pont) was used as received. $1 \mathrm{M}$ solution of $\mathrm{Li}\left[\mathrm{Tf}_{2} \mathrm{~N}\right]$ (Aldrich) in [EMIm] $\left[\mathrm{Tf}_{2} \mathrm{~N}\right]$ (Io-li-tec) and was dried and degassed for 10 minutes at $433 \mathrm{~K}$ under vacuum. The same procedure applied to [DEME] $\left[\mathrm{Tf}_{2} \mathrm{~N}\right],[\mathrm{PP} 13]\left[\mathrm{Tf}_{2} \mathrm{~N}\right]$ and $[\mathrm{BMP}]\left[\mathrm{Tf}_{2} \mathrm{~N}\right]$.

The organic cathode pastes were prepared by blending quinonic compounds with Ketjen Black (KB, $1270 \mathrm{~m}^{2} / \mathrm{g}$ ) and solution casting in THF. The quinone-KB mixture suspension in THF was dried at $363 \mathrm{~K}$ in air for $2 \mathrm{~h}$ and further by vacuum drying at $343 \mathrm{~K}$. The residue was ground with PTFE by a pestle and mortar until paste formed. The typical thickness was $\sim 300 \mu \mathrm{m}$. The compositions of TCNQ cathode pastes described in the text as " 88.7 wt.\%, 47.6 wt.\% and 29.1 wt.\%" were as follows: in the order of TCNQ, KB and PTFE, 88.7 wt. $\%+6.6$ wt. $\%+4.7$ wt. $\%, 47.6$ wt. $\%+$ 46.9 wt. $\%+5.6$ wt. $\%, 29.1$ wt. $\%+65.3$ wt. $\%+5.6$ wt. $\%$.

The detailed procedure for preparation of silica-RTIL composite quasi-solid electrolyte is described elsewhere ${ }^{25}$. The mean diameter of fumed silica nanoparticles was $\sim 6 \mathrm{~nm}$ and the silica-RTIL ratio was $1: 3$ by volume. The electrolyte was stored at $433 \mathrm{~K}$ under vacuum. The thickness of the solid electrolyte in an assembled cell was typically $\sim 400 \mu \mathrm{m}$.

PEO membranes were prepared by dissolving PEG $(\mathrm{MW}=6000), \mathrm{PEO}(\mathrm{Mw}=$ $4,000,000)$, and $\mathrm{Li}\left[\mathrm{Tf}_{2} \mathrm{~N}\right]$ at 1:8:1 ratio in acetonitrile and vacuum-drying at $343 \mathrm{~K}$ to give a white powder with typical conductivity of $\sim 1 \times 10^{-3} \mathrm{~S} / \mathrm{cm}$ at room temperature. The PEO residue was compressed at $2000 \mathrm{~N}$ at $333 \mathrm{~K}$ to form a film with typical thickness of $\sim 20 \mu \mathrm{m}$. The cathode current collector disc was prepared by grinding a 4:1 mixture of carbon (acetylene black) and PTFE in pestle and mortar and drying in vacuum at $433 \mathrm{~K}$ overnight.

Characterisation: $\mathrm{X}$-ray diffraction patterns at wide-angle $\left(5^{\circ} \sim 50^{\circ}\right)$ were collected on a D8-ADVANCE powder X-ray diffractometer operating at $40 \mathrm{kV}$ and $30 \mathrm{~mA}$ and using $\mathrm{Cu}-\mathrm{K}$ radiation source $(\lambda=0.15406 \mathrm{~nm})$. Morphology observation and composition analysis were performed using a scanning electron microscope (field emission SEM, SU-6600, Hitachi) at $10 \mathrm{kV}$ accelerating voltage, and an energy dispersive X-ray spectrometer (EDS, Inca X-act, Oxford Instruments), respectively.

Electrochemistry: The cathode-electrolyte combined disc was assembled by stacking solid electrolyte, PEO film, cathode paste and a cathode current collector disc in a die with the internal diameter of $10 \mathrm{~mm}$. The entire stack was compressed in the die at $100 \mathrm{MPa}$ to form a pellet. $10 \mu \mathrm{l}$ of [EMIm] $\left[\mathrm{Tf}_{2} \mathrm{~N}\right] 1 \mathrm{M} \mathrm{Li}\left[\mathrm{Tf}_{2} \mathrm{~N}\right]$ solution was dropped on the electrolyte side and the pellet was left in vacuum for $\sim 15$ minutes to remove any remaining bubbles. $5 \mu \mathrm{l}$ of $\mathrm{EC} / \mathrm{DEC} 1 \mathrm{M} \mathrm{LiClO}_{4}$ was dripped on a freshly cut shiny lithium metal and the pellet was placed over. The cell was sealed in a CR2032 coin cell under argon atmosphere for electrochemical measurements (Supplementary fig. S2)
2. Chen, H. et al. From Biomass to a Renewable LiXC6O6 Organic Electrode for Sustainable Li-Ion Batteries. ChemSusChem 1, 348-355 (2008).

3. Ratnakumar, B. V., Di Stefano, S., Williams, R. M., Nagasubramanian, G. \& Bankston, C. P. Organic cathode materials in sodium batteries. J. Appl. Electrochem. 20, 357-364 (1990).

4. Quartarone, E. \& Mustarelli, P. Electrolytes for solid-state lithium rechargeable batteries: recent advances and perspectives. Chem. Soc. Rev 40, 2525-2540 (2011).

5. Chen, H. et al. Lithium Salt of Tetrahydroxybenzoquinone: Toward the Development of a Sustainable Li-Ion Battery. J. Am. Chem. Soc. 131, 8984-8988 (2009).

6. Yao, M. et al. High-capacity organic positive-electrode material based on a benzoquinone derivative for use in rechargeable lithium batteries. J. Power Sources 195, 8336-8340 (2010).

7. Wu, F. et al. Sulfur/Polythiophene with a Core/Shell Structure: Synthesis and Electrochemical Properties of the Cathode for Rechargeable Lithium Batteries. J. Phys. Chem. C 115, 6057-6063 (2011).

8. Senoh, H., Yao, M., Sakaebe, H., Yasuda, K. \& Siroma, Z. A two-compartment cell for using soluble benzoquinone derivatives as active materials in lithium secondary batteries. Electrochim. Acta 56, 10145-10150 (2011)

9. Renault, S., Geng, J., Dolhem, F. \& Poizot, P. Evaluation of polyketones with Ncyclic structure as electrode material for electrochemical energy storage: case of pyromellitic diimide dilithium salt. Chem. Commun. 47, 2414-2416 (2011).

10. Zhang, J. et al. Poly (ethene-1,1,2,2-tetrathiol): Novel cathode material with high specific capacity for rechargeable lithium batteries. J. of Power Sources 186, 496499 (2009).

11. Han, X., Chang, C., Yuan, L., Sun, T. \& Sun, J. Aromatic Carbonyl Derivative Polymers as High-Performance Li-Ion Storage Materials. Adv. Mater. 19, 16161621 (2007).

12. Morita, Y. et al. Organic tailored batteries materials using stable open-shell molecules with degenerate frontier orbitals. Nat. Mater. 10, 947-651 (2011).

13. Lei, Z. et al. A MC/AQ Parasitic Composite as Cathode Material for Lithium Battery. J. Electrochem. Soc. 158, A991-A996 (2011).

14. Genorio, B., Pirnat, K., Cerc-Korosec, R., Dominko, R. \& Gaberscek, M. Electroactive Organic Molecules Immobilized onto Solid Nanoparticles as a Cathode Material for Lithium-Ion Batteries. Angew. Chem. Int. Ed. 49, 7222-7224 (2010).

15. Zhan, L. et al. PEDOT: Cathode active material with high specific capacity in novel electrolyte system. Electrochim. Acta 53, 8319-8323 (2008).

16. $\mathrm{Yu}, \mathrm{X}$. et al. Lithium storage in conductive sulfur-containing polymers. J. Electroanal. Chem. 573, 121-128 (2004).

17. Song, Z., Zhan, H. \& Zhou, Y. Anthraquinone based polymer as high performance cathode material for rechargeable lithium batteries. Chem. Comm. 448-450 (2009).

18. Le Gall, T., Reiman, K. H., Grossel, M. C. \& Owen, J. R. Poly(2,5-dihydroxy-1,4benzoquinone-3,6-methylene): a new organic polymer as positive electrode material for rechargeable lithium batteries. J. Power Sources 119-121, 316-320 (2003).

19. Washino, Y., Murata, K., Ashizawa, M., Kawauchi, S. \& Michinobu, T. Creation of persistent charge-transfer interactions in TCNQ polyester. Polym. J. 43, 364-369 (2011).

20. Tobishima, S., Yamaki, J. \& Yamaji, A. Cathode Characteristics of Organic Electron Acceptors for Lithium Batteries. J Electrochem. Soc. 131, 57-63 (1984).

21. Khoo, S., Foley, J. K. \& Pons, S. Electrolyte effects on the cyclic voltammetry of TCNQ and TCNE. J. Electroanal. Chem. \& Interfacial Electrochem. 215, 273-285 (1986).

22. Yu, X., Bates, J. B., Jellison, Jr, G E \& Hart, F. X. A Stable Thin-Film Lithium Electrolyte: Lithium Phosphorus Oxynitride. J. Electrochem. Soc. 144, 524-532 (1997).

23. Kamaya, N. et al. A lithium superionic conductor. Nat. Mater. 10, 682-686 (2011).

24. Inaguma, Y. et al. High ionic conductivity in lithium lanthanum titanate. Solid State Comm. 86, 689-693 (1993).

25. Unemoto, A. et al. Electrical conductivity and dynamics of quasi-solidified lithium-ion conducting ionic liquid at oxide particle surfaces. Solid State Ionics 201, 11-20 (2011).

26. Le Bideau, J., Viau, L. \& Vioux, A. Ionogels, ionic liquid based hybrid materials. Chem. Soc. Rev 40, 907-925 (2011).

27. Sato, T., Maruo, T., Marukane, S. \& Takagi, K. Ionic liquids containing carbonate solvent as electrolytes for lithium ion cells. J. Power Sources 138, 253-261 (2004).

\section{Acknowledgments}

This work was conducted under the financial support of the Funding Program for World-Leading Innovative R\&D on Science and Technology (FIRST), under the Cabinet Office, Government of Japan.

\section{Author contributions}

Y. Hanyu wrote the main manuscript text and prepared all figures. All authors reviewed the manuscript. 


\section{Additional information}

Supplementary information accompanies this paper at http://www.nature.com/ scientificreports

Competing financial interests: The authors declare no competing financial interests. License: This work is licensed under a Creative Commons
Attribution-NonCommercial-ShareAlike 3.0 Unported License. To view a copy of this license, visit http://creativecommons.org/licenses/by-nc-sa/3.0/

How to cite this article: Hanyu, Y. \& Honma, I. Rechargeable quasi-solid state lithium battery with organic crystalline cathode. Sci. Rep. 2, 453; DOI:10.1038/srep00453 (2012). 